\title{
A resynchronization of ovulation program based on ovarian structures present at nonpregnancy diagnosis reduced time to pregnancy in lactating dairy cows
}

\author{
R. Wijma, M. M. Pérez, M. Masello, M. L. Stangaferro, and J. O. Giordano ${ }^{1}$ \\ Department of Animal Science, Cornell University, Ithaca, NY 14853
}

\begin{abstract}
Our objective was to evaluate time to pregnancy after the first service postpartum and pregnancy per artificial insemination $(\mathrm{P} / \mathrm{AI})$ in dairy cows managed with 2 resynchronization of ovulation programs. After first service, lactating Holstein cows were blocked by parity (primiparous vs. multiparous) and randomly assigned to the d 32 Resynch (R32; n = 1,010) or short Resynch (SR; $\mathrm{n}=1,000)$ treatments. Nonpregnancy diagnosis (NPD) was conducted $32 \pm 3 \mathrm{~d}$ after AI by transrectal ultrasonography. Nonpregnant cows in R32 received the Ovsynch protocol: $\mathrm{GnRH}, \mathrm{PGF}_{2 \alpha} 7 \mathrm{~d}$ later, GnRH 56 h later, and timed AI (TAI) 16 to $18 \mathrm{~h}$ later. Cows in SR with a corpus luteum (CL) $\geq 15 \mathrm{~mm}$ and a follicle $\geq 10 \mathrm{~mm}$ at NPD received $\mathrm{PGF}_{2 \alpha}, \mathrm{PGF}_{2 \alpha} 24 \mathrm{~h}$ later, GnRH $32 \mathrm{~h}$ later, and TAI 16 to $18 \mathrm{~h}$ later. Cows in SR without a CL $\geq 15 \mathrm{~mm}$ or a follicle $\geq 10 \mathrm{~mm}$ at NPD received a modified Ovsynch protocol with 2 $\mathrm{PGF}_{2 \alpha}$ treatments and progesterone (P4) supplementation $\left(\mathrm{GnRH}\right.$ plus $\mathrm{CIDR}, \mathrm{PGF}_{2 \alpha}$ and CIDR removal 7 d later, $\mathrm{PGF}_{2 \alpha} 24 \mathrm{~h}$ later, GnRH $32 \mathrm{~h}$ later, and TAI 16 to $18 \mathrm{~h}$ later). Blood samples were collected from a subgroup of cows at the GnRH before TAI (R32 = $114 ; \mathrm{SR}=121)$ to measure $\mathrm{P} 4$ concentration. Binomial outcomes were analyzed with logistic regression and hazard of pregnancy $(\mathrm{R} 32=485 ; \mathrm{SR}=462)$ with Cox's proportional regression in SAS (SAS Institute, Cary, NC). For P/AI analysis, the TAI service was the experimental unit $(\mathrm{R} 32=720 ; \mathrm{SR}=819)$. Models included treatment and parity as fixed effects and farm as random effect. The hazard of pregnancy was greater for the SR treatment (hazard ratio $=1.18 ; 95 \%$ confidence interval: 1.01-1.37). Median time to pregnancy was 95 and $79 \mathrm{~d}$ for the R32 and SR treatments, respectively. At NPD, 71.3 and $71.2 \%$ of cows had a CL for the R32 and SR treatments, respectively. Treatment did not affect overall $\mathrm{P} / \mathrm{AI} 32 \pm 3 \mathrm{~d}$ after $\mathrm{AI}(\mathrm{R} 32=31.0 \%$ vs.
\end{abstract}

Received July 12, 2017.

Accepted October 12, 2017.

${ }^{1}$ Corresponding author: jog25@cornell.edu
$\mathrm{SR}=33.9 \%)$ or for cows with a $\mathrm{CL}$ at NPD (R32 = $32.7 \%$ vs. SR $=32.8 \%$ ). For cows with no CL at NPD, $\mathrm{P} / \mathrm{AI}$ was greater for the SR treatment (36.9\%) than for the R32 treatment (28.6\%). Pregnancy loss from 32 to $63 \mathrm{~d}$ after AI was similar for all services combined $(\mathrm{R} 32=8.3 \%$ vs. $\mathrm{SR}=10.4 \%)$ and for cows with no CL at NPD (R32 $=13.2 \%$ vs. $\mathrm{SR}=7.2 \%)$ but tended to be affected by treatment for cows with a CL at NPD $(\mathrm{R} 32=6.8 \%$ vs. SR $=11.9 \%)$. Treatment affected the proportion of cows with $\mathrm{P} 4 \leq 0.5 \mathrm{ng} / \mathrm{mL}$ at the $\mathrm{GnRH}$ before TAI for all cows (R32 $=68.4 \%$ vs. $\mathrm{SR}=81.8 \%)$, tended to have an effect among cows with a CL (R32 $=70.0 \%$ vs. SR $=81.8 \%$ ), and had no effect for cows with no CL $(\mathrm{R} 32=64.7 \%$ vs. SR $=81.8 \%)$. We concluded that the SR program reduced time to pregnancy because of a reduction of the interbreeding interval for cows with a CL at NPD and greater P/AI in cows with no CL at NPD.

Key words: resynchronization, corpus luteum, dairy cow, timed artificial insemination

\section{INTRODUCTION}

Dairy farm profitability depends on the reproductive performance of cows, which is primarily determined by the rate at which they become pregnant after the end of the voluntary waiting period. Despite recent gains on first-service pregnancy per AI (P/AI) due to improved dairy herd management (Wiltbank and Pursley, 2014), a substantial proportion of cows need immediate reinsemination after the first service. Therefore, to minimize the interbreeding interval, many farms use reproductive management strategies for second and greater AI services that combine insemination at detected estrus and timed AI (TAI) after resynchronization of ovulation with Ovsynch-type protocols (Pursley et al., 1995; commonly referred to as Resynch). These protocols are usually initiated at the time of or $7 \mathrm{~d}$ before nonpregnancy diagnosis (NPD; Fricke et al., 2003; Bartolome et al., 2005; Giordano et al., 2012c).

Farms that combine AI at detected estrus and TAI can initiate Resynch as early as $25 \pm 3 \mathrm{~d}$ after AI. Although 
this strategy can be beneficial because it shortens the interbreeding interval for cows that receive TAI, the first $\mathrm{GnRH}$ treatment of the protocol coincides with the time at which many cows are expected to display estrus (Remnant et al., 2015; Wijma et al., 2017). The GnRHinduced LH surge reduces estrus expression (Mendonça et al., 2012; Bruno et al., 2014; Wijma et al., 2017) through induction of ovulation or by suppressing the estradiol surge responsible for estrus behavior (Jo and Fortune, 2003). Further, the pregnancy status of cows at the time of the $\mathrm{GnRH}$ treatment $25 \pm 3 \mathrm{~d}$ after $\mathrm{AI}$ is unknown. Therefore, many pregnant cows receive an unnecessary treatment, thus increasing treatment costs and disrupting cow normal behavior.

To take advantage of a short interbreeding interval for TAI services while avoiding a reduction in the proportion of cows undergoing $\mathrm{AI}$ at detected estrus before NPD and unnecessary treatment of pregnant cows with $\mathrm{GnRH}$, we evaluated a reproductive management strategy based on the ovarian structures present at NPD $32 \pm 3$ d after AI (Wijma et al., 2017). Cows with a corpus luteum $(\mathbf{C L}) \geq 15 \mathrm{~mm}$ and a follicle $\geq 10 \mathrm{~mm}$ at NPD (hereafter referred to as CL cows) received a resynchronization of ovulation protocol without an initial GnRH treatment to induce a new follicular wave (short Resynch; $\mathrm{PGF}_{2 \alpha}, \mathrm{PGF}_{2 \alpha} 1 \mathrm{~d}$ later, GnRH $32 \mathrm{~h}$ later, and TAI 16 to $18 \mathrm{~h}$ after GnRH). On the other hand, cows not expected to respond to the short Resynch protocol based on their ovarian status (i.e., no CL $\geq 15$ $\mathrm{mm}$ or no follicle $\geq 10 \mathrm{~mm}$; hereafter referred to as noCL cows) received a modified Ovsynch protocol (i.e., 2 $\mathrm{PGF}_{2 \alpha}$ treatments $24 \mathrm{~h}$ apart) with progesterone $(\mathbf{P} 4)$ supplementation. This management strategy was compared with a similar program in which all cows received GnRH treatment $7 \mathrm{~d}$ before NPD. Removing the $\mathrm{GnRH}$ treatment $25 \pm 3 \mathrm{~d}$ after AI resulted in approximately $17 \%$ more cows inseminated at detected estrus, but it also resulted in a $\mathrm{P} / \mathrm{AI}$ reduction of approximately 8 percentage points for TAI services in CL cows. Nevertheless, the cumulative proportion of cows pregnant after AI at detected estrus and TAI was similar because of the greater number of pregnancies generated through insemination of cows at detected estrus before NPD in the short Resynch treatment. Although results from this experiment (Wijma et al., 2017) were promising, additional research is needed to determine whether the strategy based on ovarian status at NPD is superior to traditional programs combining AI at detected estrus and TAI after blanket use of resynchronization of ovulation. Moreover, it is necessary to corroborate that removal of the initial GnRH treatment does not compromise $\mathrm{P} / \mathrm{AI}$ for CL cows to an extent that may offset the benefit of shorter interbreeding interval.
Thus, we hypothesized that a resynchronization program based on ovarian structures present at the time of NPD (hereafter referred to as short Resynch) would reduce time to pregnancy when compared with blanket use of the d 32 Resynch protocol. Time to pregnancy would be reduced because of the shorter interbreeding interval for CL cows and increased P/AI for no-CL cows. Therefore, the objective of this experiment was to evaluate the effect of short Resynch on time to pregnancy after the first service, P/AI, and physiological outcomes before TAI.

\section{MATERIALS AND METHODS}

This experiment was conducted from February 2016 to May 2017 on 2 commercial dairy farms located in Tompkins and Cayuga counties in New York. All procedures were approved by the Animal Care and Use Committee of the College of Agriculture and Life Sciences at Cornell University (Ithaca, NY).

On both farms, cows were housed in freestall barns and were fed a TMR once a day with ad libitum access to feed and water. Farm A milked approximately 1,300 cows, with an average milk yield of approximately 43 $\mathrm{kg} / \mathrm{d}$. Cows were milked 3 times per day at approximately 8-h intervals until February 2017, when milking frequency changed to 4 times per day at approximately 6-h intervals. All cows received recombinant bST (500 mg of sometribove zinc; Posilac, Elanco Animal Health, Indianapolis, IN) at 10- or 11-d intervals beginning at $80 \pm 3$ DIM in primiparous cows and $110 \pm 3$ DIM in multiparous cows until dry-off. Primiparous cows received first service at $82 \pm 3$ DIM and multiparous cows received first service at $67 \pm 3$ DIM after synchronization of ovulation with the Double Ovsynch protocol (Souza et al., 2008). Farm B milked approximately 1,900 cows 3 times per day at approximately 8-h intervals and had an average milk yield per cow of approximately $42 \mathrm{~kg} / \mathrm{d}$. All cows received recombinant bST at 14-d intervals beginning at $60 \pm 3$ DIM until dry-off. Primiparous and multiparous cows were synchronized with the Presynch-Ovsynch protocol (Moreira et al., 2001). Cows were eligible to receive AI after the first and second $\mathrm{PGF}_{2 \alpha}$ treatments of Presynch-Ovsynch at $53 \pm 3$ and $67 \pm 3$ DIM, respectively, whereas cows not detected in estrus received TAI at $79 \pm 3$ DIM. During the experiment, $86.5 \%(1,103 / 1,274)$ of the cows enrolled received the first service at detected estrus, whereas the remaining $13.4 \%(171 / 1,274)$ of the cows received TAI.

Every week, cows that received a previous AI service were blocked by parity (primiparous vs. multiparous) and randomly assigned to the d 32 Resynch (R32) or 
short Resynch (SR) treatments. Cows remained in the same treatment until the end of the experiment. Cows that received their first service postpartum at or after the beginning of the experiment $(\mathrm{R} 32=1,010$; $\mathrm{SR}=$ $1,000)$ were included for the evaluation of time to pregnancy. Conversely, cows that had already received their first service before the beginning of the experiment were enrolled, but only data from individual TAI services were collected $(\mathrm{R} 32=207 ; \mathrm{SR}=270)$ for subsequent analysis of $\mathrm{P} / \mathrm{AI}$ and pregnancy loss. All cows detected in estrus after a previous AI were immediately inseminated. On farm A, detection of estrus was conducted using a combination of visual observation and physical activity monitoring with leg-mounted activity tags (Afi-ActII, Afikim, Kibbutz Afikim, Israel), whereas on farm B, detection of estrus was conducted through visual observation and tail paint removal. Nonpregnancy diagnosis was performed by transrectal ultrasonography (TUS; Ibex Pro, Ibex, Loveland, CO) $32 \pm 3 \mathrm{~d}$ after AI in cows from both experimental treatments not previously reinseminated at detected estrus. In nonpregnant cows, size of follicles and corpora lutea present at NPD was estimated using the ultrasound machine goggle's screen grid lines comprising squares of $10 \mathrm{~mm}$ by 10 $\mathrm{mm}$. Pregnant cows received no further treatment. All TUS examinations were conducted by veterinarians. On farm A the veterinarian was one of the coauthors, whereas on farm $\mathrm{B}$ the veterinarians were one of the coauthors and the practicing veterinarian.

Nonpregnant cows from the SR experimental treatment were classified and then treated based on the ovarian structures present at NPD (Figure 1). Cows with at least $1 \mathrm{CL} \geq 15 \mathrm{~mm}$ and at least 1 ovarian follicle $\geq 10 \mathrm{~mm}$ in diameter (CL cows) received $\mathrm{PGF}_{2 \alpha}$ $(500 \mu \mathrm{g}$ of cloprostenol sodium; Estrumate, Merck Animal Health, Summit, NJ) immediately after NPD, a second $\mathrm{PGF}_{2 \alpha} 24 \mathrm{~h}$ later, GnRH $(100 \mu \mathrm{g}$ of gonadorelin diacetate tetrahydrate; Fertagyl, Merck Animal Health) $32 \mathrm{~h}$ after the second $\mathrm{PGF}_{2 \alpha}$, and TAI 16 to $18 \mathrm{~h}$ later (Figure 1). Cows that did not meet these criteria (no-CL cows) received a modified Ovsynch protocol with $2 \mathrm{PGF}_{2 \alpha}$ treatments and $\mathrm{P} 4$ supplementation through an intravaginal P4-releasing device (1.38 $\mathrm{g}$ of P4; Eazi-Breed CIDR, Zoetis, Florham Park, NJ) from the time of the first $\mathrm{GnRH}$ to the first $\mathrm{PGF}_{2 \alpha}$ treatment of the protocol (GnRH plus CIDR, $\mathrm{PGF}_{2 \alpha}$ and CIDR removal 7 d later, $\mathrm{PGF}_{2 \alpha} 24$ h later, GnRH 32 h later, and TAI 16 to $18 \mathrm{~h}$ later; Figure 1). Cows detected in estrus after NPD and before TAI were immediately inseminated. Every time a cow in the SR treatment was diagnosed as nonpregnant it was classified as CL or no-CL and received the stipulated treatment based on ovarian status.
Nonpregnant cows in the R32 treatment were immediately enrolled in the d 32 Resynch protocol ( $\mathrm{GnRH}$, $\mathrm{PGF}_{2 \alpha} 7 \mathrm{~d}$ later, GnRH 56 h later, and TAI 16 to 18 $\mathrm{h}$ later; Figure 1) to receive TAI. A combination of AI at detected estrus and TAI after the d 32 Resynch protocol without differential treatment based on ovarian structures was selected as a control treatment because it is one of the most commonly used strategies to manage second and greater AI services in lactating dairy cows in the United States (Caraviello et al., 2006; Ferguson and Skidmore, 2013; Scott, 2016).

Reconfirmation of pregnancy was performed $63 \pm 3$ $\mathrm{d}$ after AI by TUS in both farms. A cow was considered to have undergone pregnancy loss when confirmed pregnant at the initial examination and nonpregnant at the time of reconfirmation. Cows with an insemination after a detected estrus between the 2 pregnancy examinations were also considered to have suffered pregnancy loss. Cows diagnosed pregnant $32 \pm 3 \mathrm{~d}$ after AI but not pregnant at the time of pregnancy reconfirmation (i.e., $63 \pm 3 \mathrm{~d}$ after AI) were immediately enrolled in the Ovsynch protocol. Cows with detected pregnancy loss failing to conceive after TAI with the Ovsynch protocol were resynchronized after NPD per their experimental treatment (i.e., R32 or SR).

\section{TUS and Blood Sample Collection for Monitoring Ovarian Responses}

Ovarian responses were monitored at the time of NPD and the GnRH treatment before TAI in a subgroup of cows from each treatment (153 and 146 in R32 and SR, respectively) on farm A. Transrectal ultrasonography was conducted to record size (diameter) of the largest follicle and corpora lutea present on the ovaries. Size of follicles and corpora lutea was estimated using the ultrasound machine (same used for NPD) goggle screen grid lines comprising squares of $10 \mathrm{~mm}$ by $10 \mathrm{~mm}$. If the largest follicle was greater than $25 \mathrm{~mm}$ and thereby a potential follicular cyst, the second largest follicle was considered the dominant follicle for analysis. From the same group of cows, blood samples were collected to determine circulating concentration of P4. Blood samples were collected using 8-mL heparinized evacuated tubes (Vacutainer, Becton Dickinson, Franklin Lakes, NJ) via puncture of the coccygeal vein or artery. Samples were placed in a cooler with ice until being transported to the laboratory within $\leq 4 \mathrm{~h}$ of collection. Samples were centrifuged at $1,700 \times g$ for $20 \mathrm{~min}$ at $4^{\circ} \mathrm{C}$. Plasma aliquots were harvested and transferred to vials for storage at $-20^{\circ} \mathrm{C}$ until assays were performed. Progesterone concentration data at NPD were available for 205 cows with a CL $\geq 15 \mathrm{~mm}$ and 78 cows with no 

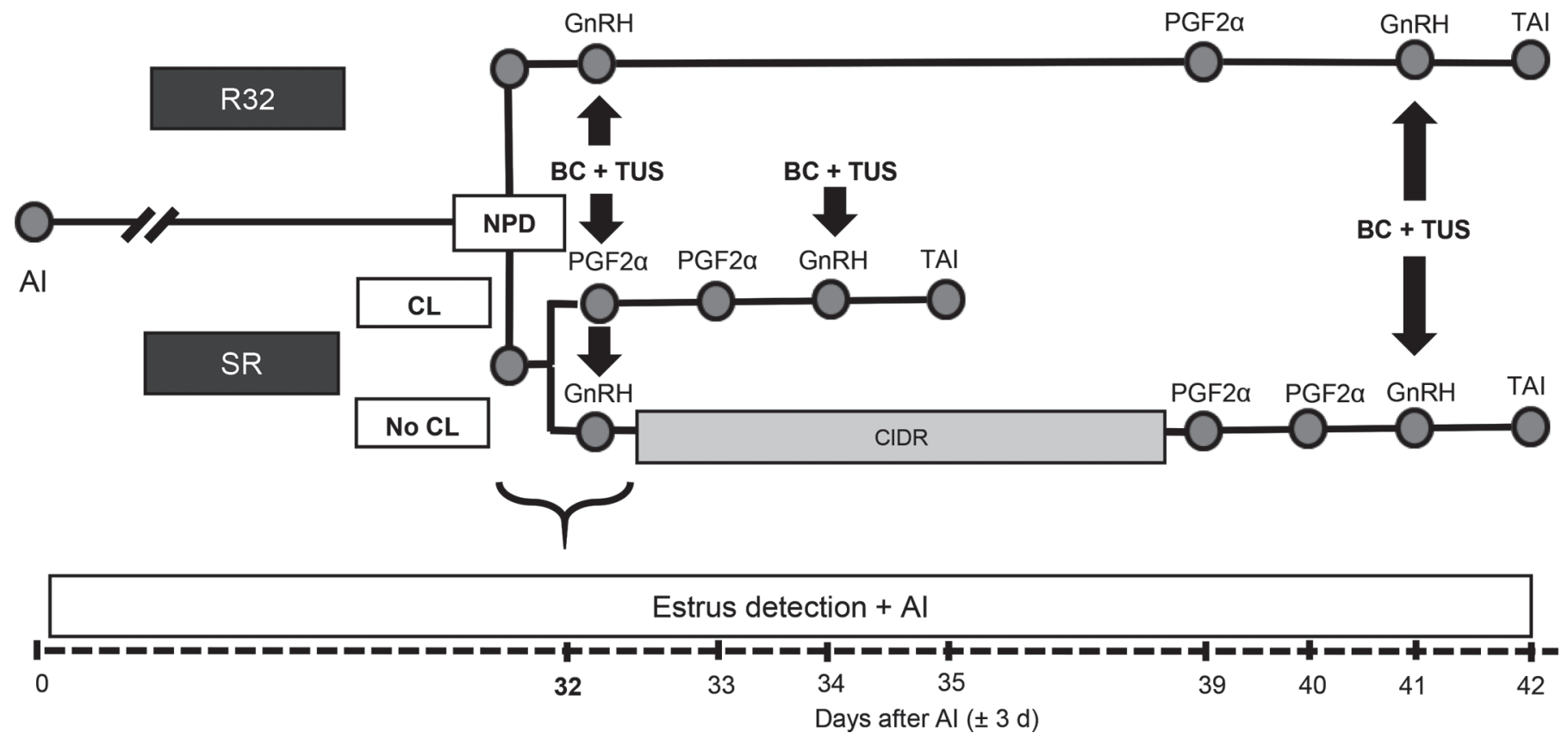

Figure 1. Graphical representation of experimental procedures. After first service, postpartum cows were stratified by parity (primiparous vs. multiparous) and randomly assigned to the $\mathrm{d} 32$ Resynch $(\mathrm{R} 32 ; \mathrm{n}=1,010)$ or short Resynch $(\mathrm{SR} ; \mathrm{n}=1,000)$ treatments. Nonpregnancy diagnosis (NPD) was performed $32 \pm 3 \mathrm{~d}$ after AI. Nonpregnant cows from the R32 treatment received the Ovsynch protocol $[\mathrm{GnRH}$, PGF $2 \alpha$ $7 \mathrm{~d}$ later, GnRH $56 \mathrm{~h}$ later, and timed AI (TAI) 16 to $18 \mathrm{~h}$ later], whereas cows in the SR treatment were resynchronized based on the ovarian structures present at NPD. Cows with at least 1 corpus luteum $>15 \mathrm{~mm}$ and 1 follicle $\geq 10 \mathrm{~mm}$ received $\mathrm{PGF}_{2 \alpha}, \mathrm{PGF}_{2 \alpha} 24 \mathrm{~h}$ later, GnRH $32 \mathrm{~h}$ later, and TAI 16 to $18 \mathrm{~h}$ after GnRH. Cows that did not fulfill these criteria received a modified Ovsynch protocol with 2 PGF ${ }_{2 \alpha}$ treatments and progesterone (P4) supplementation ( $\mathrm{GnRH}$ plus CIDR, $\mathrm{PGF}_{2 \alpha}$ and $\mathrm{CIDR}$ removal $7 \mathrm{~d}$ later, $\mathrm{PGF}_{2 \alpha} 24 \mathrm{~h}$ later, GnRH $32 \mathrm{~h}$ later, and TAI 16 to $18 \mathrm{~h}$ later). In a subgroup of cows, blood samples were collected to measure P4 concentration at NPD and at the time of GnRH treatment before TAI. Size of the largest ovarian follicle was also estimated and recorded. CL $=$ corpus luteum $\geq 15 \mathrm{~mm}$ and follicle $\geq 10 \mathrm{~mm}$; No CL $=$ cows without a corpus luteum $\geq 15 \mathrm{~mm}$ and follicle $\geq 10 \mathrm{~mm}$; TUS $=$ transrectal ultrasonography; $\mathrm{BC}=$ blood collection.

$\mathrm{CL} \geq 15 \mathrm{~mm}$ at NPD from both treatments. Data from ovarian structures and $\mathrm{P} 4$ concentration at the $\mathrm{GnRH}$ treatment before TAI was available for 114 and 121 cows from the R32 and SR treatments, respectively. The proportion of cows with a functional CL based on circulating concentration of $\mathrm{P} 4(\mathrm{P} 4 \geq 1 \mathrm{ng} / \mathrm{mL})$ was the outcome of interest at NPD. At the time of the GnRH injection before TAI, the outcomes of interest were (1) the proportion of cows with low $\mathrm{P} 4$ based on a cutoff value of $\leq 0.5 \mathrm{ng} / \mathrm{mL}$ and (2) the size of the largest ovarian follicle present. The cutoff for circulating P4 concentration at the time of the GnRH treatment before TAI was selected based on recent data suggesting that $\mathrm{P} 4$ concentrations below 0.5 to $0.4 \mathrm{ng} / \mathrm{mL}$ at this time point are associated with greater $\mathrm{P} / \mathrm{AI}$ than $\mathrm{P} 4$ levels above such cutoff points (Brusveen et al., 2009; Giordano et al., 2012c).

\section{Determination of P4 Concentration}

Concentration of P4 in plasma was determined in duplicate with a commercial solid-phase, no-extraction RIA (ImmuChem coated tube, MP Biomedicals, Costa
Mesa, CA). To assess precision of the assays, control samples with high $(5.8 \mathrm{ng} / \mathrm{mL})$ and low $(0.3 \mathrm{ng} / \mathrm{mL})$ concentrations of $\mathrm{P} 4$ were included at the beginning and end of each assay ( $\mathrm{n}=6$ assays). Average detection limit for the $\mathrm{P} 4$ assay was $0.1 \mathrm{ng} / \mathrm{mL}$. Average intra-assay coefficient of variation (CV) for the highconcentration sample was $9.7 \%$, whereas the interassay CV was $13.4 \%$. For the low-concentration sample the average intra-assay $\mathrm{CV}$ was $24.2 \%$, whereas the interassay CV was $31.3 \%$.

\section{Statistical Analysis}

This experiment was conducted as a complete randomized block design using parity (primiparous vs. multiparous) as blocking factor. According to sample size calculations conducted using the sample size calculation option of WinPepi version 11.51 (Abramson, 2011), a total of 398 cows per treatment was needed to detect a hazard ratio for pregnancy of 1.25 with an average probability of survival at the end of the experimental period of $20 \%$, probability of type I error rate of $5 \%$, and probability of type II error rate of $20 \%$. 
Cox's proportional hazards analysis for pregnancy after the first service postpartum was conducted using the PHREG procedure of SAS (version 9.4, SAS Institute Inc., Cary, NC), with treatment, parity, and milk production tercile (calculated for farm and parity group within farm) as fixed effects and farm as random effect. Milk production level was removed from the final model because $P>0.10$. Only cows that did not conceive to first AI and that had at least $210 \mathrm{~d}$ at risk of becoming pregnant after the first service were included in the analysis. A cow was considered pregnant for the analysis of time to pregnancy only if it was reconfirmed pregnant $63 \pm 3 \mathrm{~d}$ after AI. Cows that became not eligible for AI due to a farm management decision (i.e., coded as "do not breed") or that left the herd due to sale or death were right censored. Kaplan-Meier survival curves were generated to illustrate the rate of pregnancy after the first service postpartum using the survival analysis option of MedCalc (version 12.5.0.0; MedCalc Software, Ostend, Belgium).

Binary outcomes (i.e., P/AI at $32 \pm 3$ and $63 \pm 3 \mathrm{~d}$ after AI, pregnancy loss, proportion of cows inseminated at detected estrus, proportion of cows not pregnant 210 $\mathrm{d}$ after the first service, and proportion of cows with high or low P4 concentration at NPD and the GnRH before TAI) were analyzed using logistic regression with the GLIMMIX procedure of SAS. Pregnancy per $\mathrm{AI}$ at $32 \pm 3 \mathrm{~d}$ after AI was evaluated for AI services at detected estrus, TAI services, and both types of AI services combined, whereas $\mathrm{P} / \mathrm{AI}$ at $63 \pm 3 \mathrm{~d}$ after $\mathrm{AI}$ and pregnancy loss were evaluated for AI services at detected estrus and TAI combined. Treatment and parity (primiparous vs. multiparous) were included as fixed effects and farm as random effect. Days in milk at insemination $(\leq 100,>100$ and $\leq 150,>150$ and $\leq 200$, and $>200 \mathrm{~d}$ ) and season of insemination [warm (June to August) vs. cold (September to May)] were offered to the initial models for P/AI and pregnancy loss. Season was removed from all final models and DIM was removed from the pregnancy loss models because $P>$ 0.10 .

The level of agreement between TUS and P4 concentration (reference test) to detect the presence of an active CL was determined through calculation of the kappa value for interrater agreement obtained with the FREQ procedure of SAS. Size of the largest ovarian follicle at the time of GnRH before TAI was analyzed by ANOVA using the MIXED procedure of SAS, including treatment and parity as fixed effects.

All proportions reported were generated using the FREQ procedure of SAS, whereas values for quantitative outcomes are reported as arithmetic means calculated using the MEANS procedure of SAS. All explanatory variables were considered significant if $P$ $\leq 0.05$, whereas $P>0.05$ and $\leq 0.10$ was considered a tendency.

\section{RESULTS}

\section{Time to Pregnancy After First Service}

In total, 485 and 462 cows from the R32 and SR treatments, respectively, were not pregnant after the first service postpartum and were at least $210 \mathrm{~d}$ at risk of becoming pregnant after the first service postpartum unless they left the herd due to sale or death. The proportion of second and greater AI services that occurred after estrus detection $[P=0.56 ; \mathrm{R} 32=66.4 \%$ $(739 / 1,113)$ vs. $\mathrm{SR}=67.7 \%(594 / 878)]$ and $\mathrm{P} / \mathrm{AI}$ for these services $[P=0.26 ; \mathrm{R} 32=34.4 \%(277 / 805)$ vs. SR $=37.2 \%(245 / 658)]$ was similar for both treatments.

The hazard of pregnancy was greater $(P=0.03)$ for the SR treatment than for the R32 treatment (hazard ratio $=1.18 ; 95 \%$ CI: $1.01-1.37$; Figure 2 ) and was similar $(P=0.15)$ for primiparous and multiparous cows (hazard ratio $=1.12 ; 95 \%$ CI: 0.96-1.31). Median time to pregnancy was $95 \mathrm{~d}$ (95\% CI: 84-108) and $79 \mathrm{~d}(95 \%$ CI: 71-96) for the R32 and SR treatments, respectively. Mean time to pregnancy was $111 \pm 3$ and $100 \pm 3 \mathrm{~d}$ for the R32 and SR treatments, respectively. At $210 \mathrm{~d}$ after first service, a greater $(P<0.02)$ proportion of cows were not pregnant in the R32 treatment $(29.3 \%$; $142 / 485)$ than in the SR treatment $(22.3 \% ; 103 / 462)$

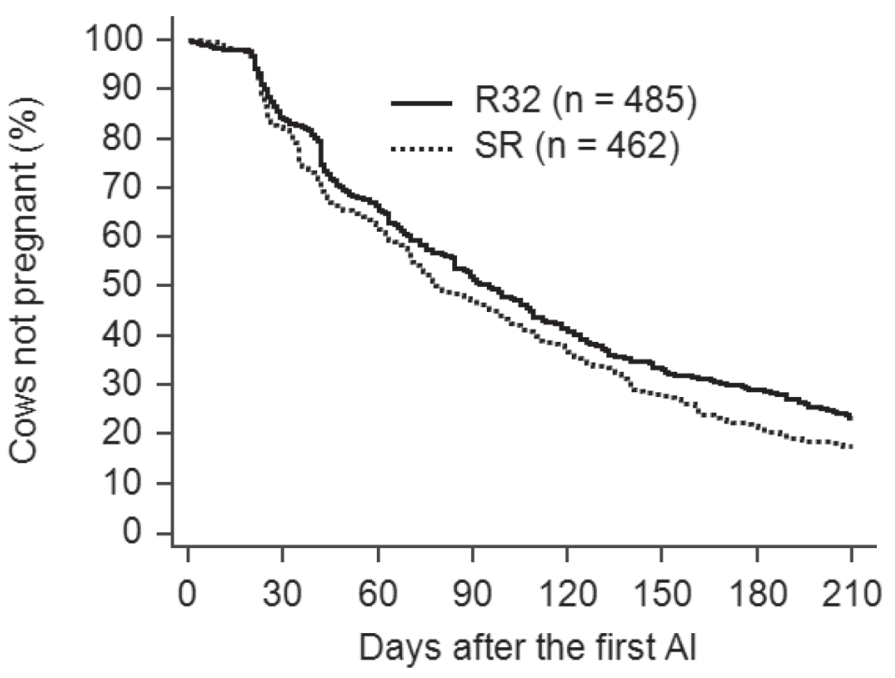

Figure 2. Kaplan-Meier survival curves for time to pregnancy from enrollment up to $210 \mathrm{~d}$ after the first service postpartum for cows in the d 32 Resynch (R32) and short Resynch (SR) treatments that failed to conceive after the first service. The hazard of pregnancy was affected $(P=0.03)$ by treatment (hazard ratio $=1.18 ; 95 \% \mathrm{CI}$ : 1.01-1.37). Median time to pregnancy was $95 \mathrm{~d}$ (95\% CI: 84-108) and 79 d (95\% CI: 71-96) for the R32 and SR treatments, respectively. Mean time to pregnancy was $111 \pm 3$ and $100 \pm 3 \mathrm{~d}$ for the R32 and SR treatments, respectively. 
Table 1. Pregnancy per AI and pregnancy loss for cows that received the experimental treatments

\begin{tabular}{|c|c|c|c|}
\hline Item & \multicolumn{2}{|c|}{ Treatment $^{1}$} & $P$-value \\
\hline All inseminations for $\mathrm{CL}^{2}$ and no-CL ${ }^{3}$ cows combined & $31.0(223 / 720)$ & $33.9(278 / 819)$ & 0.17 \\
\hline TAI & $29.6(182 / 615)$ & $33.0(247 / 748)$ & 0.14 \\
\hline All inseminations for CL cows & $32.7(168 / 513)$ & $32.8(191 / 583)$ & 0.93 \\
\hline AI at detected estrus & $37.8(28 / 74)$ & $50.0(19 / 38)$ & 0.21 \\
\hline AI at detected estrus & $41.9(13 / 31)$ & $36.4(12 / 33)$ & 0.58 \\
\hline TAI & $23.9(42 / 176)$ & $37.0(75 / 203)$ & $<0.01$ \\
\hline
\end{tabular}

${ }^{1}$ Cows were randomly assigned to the d 32 Resynch (R32) or short Resynch (SR) treatments. Nonpregnancy diagnosis was performed $32 \pm 3 \mathrm{~d}$ after AI. Nonpregnant cows in the R32 treatment received the Ovsynch protocol [GnRH, $\mathrm{PGF}_{2 \alpha} 7 \mathrm{~d}$ later, GnRH $56 \mathrm{~h}$ later, timed AI (TAI) 16 to $18 \mathrm{~h}$ later] for resynchronization of ovulation, whereas cows in the SR treatment were resynchronized based on the ovarian structures present at nonpregnancy diagnosis. Cows with at least 1 corpus luteum $\geq 15 \mathrm{~mm}$ and 1 follicle $\geq 10 \mathrm{~mm}$ received $\mathrm{PGF}_{2 \alpha}, \mathrm{PGF}_{2 \alpha} 24 \mathrm{~h}$ later, GnRH $32 \mathrm{~h}$ later, and TAI 16 to $18 \mathrm{~h}$ after GnRH. Cows that did not fulfill the corpus luteum and follicle size criteria received a modified Ovsynch protocol with $2 \mathrm{PGF}_{2 \alpha}$ treatments and progesterone supplementation (GnRH plus CIDR, $\mathrm{PGF}_{2 \alpha}$ and CIDR removal $7 \mathrm{~d}$ later, $\mathrm{PGF} 2 \alpha 24 \mathrm{~h}$ later, GnRH $32 \mathrm{~h}$ later, and TAI 16 to $18 \mathrm{~h}$ later).

${ }^{2}$ Cows with at least 1 corpus luteum $\geq 15 \mathrm{~mm}$ and 1 follicle $\geq 10 \mathrm{~mm}$.

${ }^{3}$ Cows with no corpus luteum $\geq 15 \mathrm{~mm}$ or no follicle $\geq 10 \mathrm{~mm}$.

and a greater $(P<0.01)$ proportion of multiparous cows $(29.3 \% ; 177 / 605)$ than primiparous cows $(19.9 \%$; $68 / 342)$ were not pregnant.

\section{P/AI and Pregnancy Loss}

At NPD the proportion of CL cows was $71.3 \%$ (513/720) for the R32 treatment and $71.2 \%(583 / 819)$ for the SR treatment. The rest of the cows were classified as no-CL cows in both treatments. The proportion of cows inseminated at detected estrus after NPD and before TAI was greater for the R32 treatment for all cows $[P<0.001 ; \mathrm{R} 32=14.6 \%(105 / 720) ; \mathrm{SR}=8.7 \%$ $(71 / 819)]$ and cows with a CL at NPD $[P<0.001$; R32 $=14.4 \%(74 / 513) ; \mathrm{SR}=6.5 \%(38 / 583)]$. No effect of treatment $(P=0.68)$ was observed for cows with no CL at NPD [R32 $=15.0 \%(31 / 207) ; \mathrm{SR}=14.0 \%(33 / 236)]$. For the R32 treatment, $50.9 \%$ of the AI services at detected estrus were conducted from the time of the first $\mathrm{GnRH}$ until the $\mathrm{PGF}_{2 \alpha}$ injection of the protocol, whereas the remaining $49.1 \%$ were conducted after the $\mathrm{PGF}_{2 \alpha}$ and before the morning of TAI.

Overall, P/AI $32 \pm 3$ d after AI did not differ between treatments for all (CL and no-CL cows combined) AI services $(P=0.17)$, for AI services at a detected estrus before TAI $(P=0.57)$, and for TAI services after completion of the synchronization of ovulation protocols $(P$ $=0.14$; Table 1$)$. Parity did not affect $\mathrm{P} / \mathrm{AI}(P=0.30)$ for all AI services [primiparous $=33.5 \%(211 / 630)$; multiparous $=31.9 \%(290 / 909)]$. However, DIM at TAI affected $\mathrm{P} / \mathrm{AI}$ for all AI services $(P<0.01)$ because cows inseminated at $>200$ DIM had reduced $(P<0.05)$ $\mathrm{P} / \mathrm{AI}$ when compared with cows inseminated at earlier
DIM. For AI services in cows with a CL at NPD, P/ AI was not affected $(P=0.93)$ by treatment for all inseminations, inseminations after a detected estrus $(P$ $=0.21)$, or TAI services $(P=0.94$; Table 1$)$. For AI services in cows with no CL at NPD, P/AI was greater for the SR treatment than for the R32 treatment for all inseminations $(P=0.02)$ and TAI services $(P<0.01)$, but it did not differ for inseminations after a detected estrus $(P=0.58$; Table 1$)$.

Overall, P/AI at $63 \pm 3 \mathrm{~d}$ after TAI for all AI services (CL and no-CL cows combined) was not affected by treatment $[P=0.50 ; \mathrm{R} 32=27.8 \%(198 / 713)$; SR $=29.1 \%(233 / 801)]$ or parity $[P=0.27$; primiparous $=29.6 \%(184 / 621) ;$ multiparous $=27.7 \%(247 / 893)]$. Among cows with a CL at NPD there was no effect of treatment $[P=0.40 ; \mathrm{R} 32=29.9 \%(152 / 508) ; \mathrm{SR}=$ $27.4 \%(156 / 569)]$ or parity $[P=0.12$; primiparous $=$ $31.0 \%(135 / 436)$; multiparous $=27.0 \%(173 / 641)]$ on $\mathrm{P} / \mathrm{AI}$. For cows with no CL at NPD, P/AI was greater $(P=0.01)$ for the SR treatment $(33.2 \% ; 77 / 232)$ than for the R32 treatment $(22.4 \% ; 46 / 205)$, but there was no effect of parity $[P=0.82$; primiparous $=26.5 \%$ $(49 / 185) ;$ multiparous $=29.4 \%(74 / 252)]$. Days in milk at TAI affected P/AI $63 \pm 3 \mathrm{~d}$ after AI for all AI services $(P=0.03)$ and for cows with no CL at NPD $(P<0.001)$ because cows with DIM $>200$ had reduced $(P<0.05) \mathrm{P} / \mathrm{AI}$ compared with cows inseminated at earlier DIM. On the other hand, DIM did not affect $(P$ $=0.52) \mathrm{P} / \mathrm{AI}$ for cows with a CL at NPD.

Pregnancy loss for all AI services combined (CL and no-CL cows combined) was similar for both treatments $[P=0.32 ; \mathrm{R} 32=8.3 \%(18 / 216) ; \mathrm{SR}=10.4(27 / 260)]$ and was not affected by parity $[P=0.68$; primiparous 
Various strategies for resynchronization of ovulation to maximize P/AI (Dewey et al., 2010; Giordano et al., $2012 b, c)$, shorten the interval between TAI services (Fricke et al., 2003; Galvão et al., 2007; Sinedino et al., 2014), or maximize the number of cows inseminated upon estrus detection (Bruno et al., 2013; Chebel et al., 2013; Giordano et al., 2015) have been developed and tested. Nonetheless, few experiments evaluated the effect of these strategies on time to pregnancy, which is the ultimate driver of dairy cow profitability. This is important when the interbreeding interval or the reinsemination dynamics (i.e., proportion of cows undergoing $\mathrm{AI}$ at detected estrus vs. TAI) are different for the groups compared. Indeed, cows in the SR treatment had reduced time to pregnancy, primarily due to the 7-d shorter interbreeding interval for the approximately $70 \%$ of cows with a CL at NPD despite no gain in P/ AI. The greater P/AI without extending the interbreeding interval for no-CL cows in the SR treatment also contributed to reduced time to pregnancy; however, only approximately $30 \%$ of the total nonpregnant cows benefited from greater $\mathrm{P} / \mathrm{AI}$.

The similar $\mathrm{P} / \mathrm{AI}$ for $\mathrm{CL}$ cows in both treatments was critical for reducing time to pregnancy for SR because if cows that received this protocol had reduced $\mathrm{P} / \mathrm{AI}$, the benefit of shorter interbreeding interval could have been counterbalanced by the reduced proportion of pregnant cows after TAI. For CL cows in the SR treatment, the detriment of suboptimal control of the follicular wave dynamics (Wijma et al., 2017) must have been compensated, at least in part, by the $2 \mathrm{PGF}_{2 \alpha}$ treatments. Indeed, the proportion of cows with a CL at NPD that had low $\mathrm{P} 4$ concentration at the time of $\mathrm{GnRH}$ treatment before TAI tended to be greater in the SR treatment. We speculate that maximizing the proportion of cows with low $\mathrm{P} 4$ concentration at the time of inducing ovulation before TAI had a greater effect on P/AI than reduced control of the follicular wave from which the ovulatory follicle emerged. In this regard, previous experiments with resynchronized lactating dairy cows reported greater $\mathrm{P} / \mathrm{AI}$ for cows that failed to ovulate to the first GnRH treatment of Ovsynch but had complete luteolysis before TAI than for cows that ovulated but had incomplete luteolysis before TAI (Giordano et al., 2012c). Other potential issues with synchronization of ovulation protocols that do not tightly control follicular wave dynamics before TAI include lack of ovulation to the GnRH before TAI and the potential to increase pregnancy losses due to poor oocyte quality or luteal insufficiency after AI. Cows in which the follicular wave of the ovulatory follicle began less than $5 \mathrm{~d}$ before induction of luteolysis may have either failed to ovulate in response to the GnRH before TAI (Vasconcelos et al., 1999) or ovulated a small follicle that resulted in a small CL incapable of supporting pregnancy (Vasconcelos et al., 2001). Cows that initiated the follicular wave of the ovulatory follicle more than $5 \mathrm{~d}$ before induction of luteolysis may have been more likely to have poor embryo quality because of ovulation of an aged oocyte (Cerri et al., 2009). These issues were expected for some CL cows in the SR treatment because GnRH was not given to induce a follicular wave from which the ovulatory follicle would emerge. In this regard, we recently reported greater variation for age of the largest follicle and greater follicle size at NPD $32 \pm 3 \mathrm{~d}$ after AI in cows that did not receive GnRH compared with cows that received GnRH 7 d earlier (Wijma et al., 2017).

We speculate that the tendency for greater pregnancy loss in the SR treatment for CL cows could be explained, at least in part, by reduced control of the follicular wave dynamics before TAI. In our experiment, however, differences in pregnancy loss between groups may have also been less dramatic because the follicular wave dynamics of cows resynchronized with Ovsynchtype protocols is not optimal due to ovulatory failure in response to the first GnRH of the protocol in a high proportion of previously inseminated cows (Giordano et al., 2012c; Wijma et al., 2017). In particular, poor ovulatory response has been reported for cows with a functional CL at the time of the GnRH treatment (Galvão and Santos, 2010; Giordano et al., 2012c).

Despite no reduction of the interbreeding interval for no-CL cows, the increment in P/AI for these cows likely contributed to the reduction of time to pregnancy for the SR treatment. Greater P/AI for resynchronized services at the same interbreeding interval reduces time to pregnancy by decreasing the need for reinseminations at a later time. In cows with no CL at NPD, the beneficial effect of $\mathrm{P} 4$ supplementation and $2 \mathrm{PGF}_{2 \alpha}$ treatments likely synergized. Supplemental P4 in cows without a CL at the initiation of Ovsynch-type protocols has been proven effective for increasing $\mathrm{P} / \mathrm{AI}$ (Bartolome et al., 2009; Bisinotto et al., 2013, 2015) due to a combination of (1) improved embryo quality because of improved endocrine environment for oocyte development (Rivera et al., 2011), (2) improved uterine environment (Cerri et al., 2011), and (3) reduced premature estrus and ovulation before TAI (Stevenson et al., 2006). The latter, however, may not have been as relevant in the current experiment because cows detected in estrus any time were immediately inseminated and had reasonable P/AI. An additional $\mathrm{PGF}_{2 \alpha}$ treatment after induction of luteolysis is known to increase the proportion of cows with complete luteolysis before TAI (Brusveen et al., 2009; Ribeiro et al., 2012; Wiltbank et al., 2015), which in turn increases P/AI (Souza et al., 2007; Brusveen et al., 2009). In our experiment, the additional $\mathrm{PGF}_{2 \alpha}$ treatment may explain a substan- 
tial portion of the gain in $\mathrm{P} / \mathrm{AI}$ for no-CL cows. These cows are more likely to ovulate after GnRH (Galvão and Santos, 2010; Giordano et al., 2012c; Lopes et al., 2013) due to a greater GnRH-induced LH response (Giordano et al., 2012a; Lima et al., 2013; Pulley et al., 2015) and thereby are more likely to have only one 6-d-old CL not fully responsive to $\mathrm{PGF}_{2 \alpha}$ at the time of induction of luteolysis. That may explain the relatively low proportion of cows with low P4 at the time of the GnRH before TAI even after $2 \mathrm{PGF}_{2 \alpha}$ treatments. Our results should be interpreted with caution because they do not necessarily represent actual luteal regression (no data for P4 at NPD).

In the current experiment, the proportion of nonpregnant cows bearing a CL $32 \pm 3 \mathrm{~d}$ after AI observed was in agreement with previous research (Bruno et al., 2014; Giordano et al., 2015; Wijma et al., 2017). Nevertheless, the agreement between TUS and P4 concentration for the determination of the presence of an active CL was only moderate and lower than that previously reported (Bicalho et al., 2008; Giordano et al., 2015). Lack of agreement between TUS and P4 was expected for some cows because of the limitations of B-mode ultrasonography to predict $\mathrm{P} 4$ secretion by luteal tissue (Battocchio et al., 1999), lack of a strong linear correlation between CL size and P4 secretion (Sprecher et al., 1989; Mann, 2009), and the ability of fluid-filled cavities with no apparent or a small amount of luteal tissue to produce P4 (Farin et al., 1990; Giordano et al., 2016). For example, the $11.4 \%$ of cows with $\mathrm{P} 4<0.5 \mathrm{ng} / \mathrm{mL}$ and a CL $\geq 15 \mathrm{~mm}$ may have had a CL that completed functional but not structural luteolysis, whereas the $3.9 \%$ of cows with $\mathrm{P} 4 \geq 0.5$ and $<1 \mathrm{ng} / \mathrm{mL}$ were likely to have a CL from a recent ovulation. Applying the protocol for CL cows in SR may have been detrimental for these cows because some may have already had a regressed CL at NPD, whereas incomplete luteolysis could have been limiting in cows with an immature CL at the time of $\mathrm{PGF}_{2 \alpha}$ treatment (Henricks et al., 1974; Wiltbank et al., 2015). Although not evaluated in this experiment, we speculate that these 2 subgroups of cows may have had better performance if they would have received the treatment for no-CL cows. In particular, the group with an immature CL because of more time until induction of luteolysis would have allowed the CL to become fully responsive to $\mathrm{PGF}_{2 \alpha}$. On the other hand, almost half (i.e., $43.5 \%$ ) of the cows with no CL $\geq 15$ $\mathrm{mm}$ visualized through TUS and $\mathrm{P} 4 \geq 1 \mathrm{ng} / \mathrm{mL}$ had a fluid-filled cavity $\geq 25 \mathrm{~mm}$ (usually considered ovarian cysts) with the potential to produce $\mathrm{P} 4$. The rest of the cows with $\mathrm{P} 4>0.5 \mathrm{ng} / \mathrm{mL}$ may have had a small CL that was formed after a recent ovulation but not easily visualized through TUS or a CL $<15 \mathrm{~mm}$ in diameter. Unfortunately, it is not possible to determine whether cows with a small but mature CL visualized through TUS would have benefited from earlier reinsemination if they received the resynchronization protocol for CL cows rather than receiving the treatment for no-CL cows. Conversely, the other subgroups of cows likely benefited from receiving the modified Ovsynch protocol with $\mathrm{P} 4$ supplementation.

Although our control group could have easily incorporated the modified protocol with $2 \mathrm{PGF}_{2 \alpha}$ treatments for all cows and P4 supplementation for no-CL cows, our reason for not doing so was to keep the treatment as simple as possible and reflect the conditions of many dairy herds in the United States that use this strategy for resynchronization of ovulation (Caraviello et al., 2006; Ferguson and Skidmore, 2013; Scott, 2016). Most farms likely choose to either not treat cows based on their ovarian status at NPD $32 \pm 3 \mathrm{~d}$ after AI or conduct NPD $39 \pm 3 \mathrm{~d}$ coincident with the time of the $\mathrm{PGF}_{2 \alpha}$ treatment before TAI. Whether differential treatment of no-CL cows in the R32 treatment would have offset the gain in reproductive performance from the 7-d shorter interbreeding interval in the SR treatment is unknown. Nevertheless, it is rather unlikely because most of the cows had a CL at NPD; therefore, they benefited by the reduced interbreeding interval of the SR protocol.

Finally, another important consideration for the use of the SR treatment as a management strategy is the potential extra cost of the program compared with blanket use of d 32 Resynch. The expected reduction in time to pregnancy and proportion of cows not pregnant in late lactation must offset the additional cost of the protocol for no-CL cows and the potential extra cost of TUS in farms that do not routinely use this method of NPD. Thus, the economics of more complex and potentially more expensive management strategies such as SR warrant further investigation.

\section{CONCLUSIONS}

A reproductive management program designed to (1) reduce the interbreeding interval for TAI services in cows with a CL $\geq 15 \mathrm{~mm}$ and a follicle $\geq 10 \mathrm{~mm}$ at NPD and (2) increase P/AI of cows without a CL at NPD through a modified Ovsynch protocol with $2 \mathrm{PGF}_{2 \alpha}$ treatments and $\mathrm{P} 4$ supplementation reduced time to pregnancy and the proportion of nonpregnant cows $210 \mathrm{~d}$ after first service compared with blanket use of the d 32 Resynch protocol. Therefore, the SR program is a new management strategy with the potential to improve reproductive performance of dairy herds that enroll nonpregnant cows not reinseminated at detected estrus in Ovsynch-type resynchronization of ovulation protocols regardless of their ovarian status. In addition, 
removing the GnRH treatment to induce a new follicular wave in the SR treatment helped reduce the interbreeding interval without disrupting estrus behavior and reduced unnecessary treatment of pregnant cows with GnRH $25 \pm 3$ d after AI.

\section{ACKNOWLEDGMENTS}

We extend our gratitude to the owners and personnel from the 2 commercial farms that participated in our experiment for access to their cows and facilities and their continuous support of this research. We also extend our gratitude to Merck Animal Health (Madison, NJ) and Zoetis (Parsippany-Troy Hills, NJ) for supporting this research. This material is based on work supported by the National Institute of Food and Agriculture, USDA (Washington, DC) Hatch under 1007421 and Multistate 100572 to J. O. G. Any opinions, findings, conclusions, or recommendations expressed in this publication are those of the authors and do not necessarily reflect the view of the National Institute of Food and Agriculture or the USDA.

\section{REFERENCES}

Abramson, J. H. 2011. WINPEPI updated: Computer programs for epidemiologists, and their teaching potential. Epidemiol. Perspect. Innov. 8:1.

Bartolome, J. A., F. Silvestre, S. Kamimura, A. Arteche, P. Melendez, D. Kelbert, J. McHale, K. Swift, L. Archbald, and W. Thatcher. 2005. Resynchronization of ovulation and timed insemination in lactating dairy cows: I: Use of the Ovsynch and Heatsynch protocols after non-pregnancy diagnosis by ultrasonography. Theriogenology 63:1617-1627.

Bartolome, J. A., J. Van Leeuwen, M. Thieme, O. Sa'Filho, P. Melendez, L. Archbald, and W. Thatcher. 2009. Synchronization and resynchronization of inseminations in lactating dairy cows with the CIDR insert and the Ovsynch protocol. Theriogenology 72:869878

Battocchio, M., G. Gabai, A. Mollo, M. Veronesi, F. Soldano, G. Bono, and F. Cairoli. 1999. Agreement between ultrasonographic classification of the CL and plasma progesterone concentration in dairy cows. Theriogenology 51:1059-1069.

Bicalho, R. C., K. Galvao, C. Guard, and J. Santos. 2008. Optimizing the accuracy of detecting a functional corpus luteum in dairy cows. Theriogenology 70:199-207.

Bisinotto, R. S., L. Castro, M. Pansani, C. Narciso, N. Martinez, L. Sinedino, T. Pinto, N. Van de Burgwal, H. Bosman, and R. Surjus. 2015. Progesterone supplementation to lactating dairy cows without a corpus luteum at initiation of the Ovsynch protocol. J. Dairy Sci. 98:2515-2528.

Bisinotto, R. S., E. Ribeiro, F. Lima, N. Martinez, L. Greco, L. Barbosa, P. Bueno, L. Scagion, W. Thatcher, and J. Santos. 2013. Targeted progesterone supplementation improves fertility in lactating dairy cows without a corpus luteum at the initiation of the timed artificial insemination protocol. J. Dairy Sci. 96:2214-2225.

Bruno, R. G., A. Farias, J. Hernández-Rivera, A. Navarrette, D. Hawkins, and T. Bilby. 2013. Effect of gonadotropin-releasing hormone or prostaglandin F $2 \alpha$-based estrus synchronization programs for first or subsequent artificial insemination in lactating dairy cows. J. Dairy Sci. 96:1556-1567.

Bruno, R. G., J. Moraes, J. Hernández-Rivera, K. Lager, P. Silva, A. Scanavez, L. Mendonça, R. Chebel, and T. Bilby. 2014. Effect of an Ovsynch56 protocol initiated at different intervals after insemination with or without a presynchronizing injection of gonadotropin-releasing hormone on fertility in lactating dairy cows. J. Dairy Sci. 97:185-194.

Brusveen, D. J., A. Souza, and M. Wiltbank. 2009. Effects of additional prostaglandin F $2 \alpha$ and estradiol- $17 \beta$ during Ovsynch in lactating dairy cows. J. Dairy Sci. 92:1412-1422.

Caraviello, D. Z., K. Weigel, P. Fricke, M. Wiltbank, M. Florent, N. Cook, K. Nordlund, N. Zwald, and C. Rawson. 2006. Survey of management practices on reproductive performance of dairy cattle on large US commercial farms. J. Dairy Sci. 89:4723-4735.

Cerri, R. L., R. Chebel, F. Rivera, C. Narciso, R. Oliveira, M. Amstalden, G. Baez-Sandoval, L. Oliveira, W. Thatcher, and J. Santos. 2011. Concentration of progesterone during the development of the ovulatory follicle: II. Ovarian and uterine responses. J. Dairy Sci. 94:3352-3365.

Cerri, R. L., H. M. Rutigliano, R. C. Chebel, and J. E. Santos. 2009 Period of dominance of the ovulatory follicle influences embryo quality in lactating dairy cows. Reproduction 137:813-823.

Chebel, R. C., A. Scanavez, P. Silva, J. Moraes, L. Mendonça, and G. Lopes. 2013. Evaluation of presynchronized resynchronization protocols for lactating dairy cows. J. Dairy Sci. 96:1009-1020.

Dewey, S. T., L. Mendonça, G. Lopes, F. Rivera, F. Guagnini, R Chebel, and T. Bilby. 2010. Resynchronization strategies to improve fertility in lactating dairy cows utilizing a presynchronization injection of GnRH or supplemental progesterone: I. Pregnancy rates and ovarian responses. J. Dairy Sci. 93:4086-4095.

Farin, P. W., R. Youngquist, J. Parfet, and H. Garverick. 1990. Diagnosis of luteal and follicular ovarian cysts in dairy cows by sector scan ultrasonography. Theriogenology 34:633-642.

Ferguson, J. D., and A. Skidmore. 2013. Reproductive performance in a select sample of dairy herds. J. Dairy Sci. 96:1269-1289.

Fricke, P. M., D. Caraviello, K. Weigel, and M. Welle. 2003. Fertility of dairy cows after resynchronization of ovulation at three intervals following first timed insemination. J. Dairy Sci. 86:3941-3950.

Galvão, K. N., and J. Santos. 2010. Factors affecting synchronization and conception rate after the Ovsynch protocol in lactating Holstein cows. Reprod. Domest. Anim. 45:439-446.

Galvão, K. N., J. Santos, R. Cerri, R. Chebel, H. Rutigliano, R. Bruno, and R. Bicalho. 2007. Evaluation of methods of resynchronization for insemination in cows of unknown pregnancy status. J. Dairy Sci. 90:4240-4252.

Giordano, J. O., P. Fricke, J. Guenther, G. Lopes, M. Herlihy, A. Nascimento, and M. Wiltbank. 2012a. Effect of progesterone on magnitude of the luteinizing hormone surge induced by two different doses of gonadotropin-releasing hormone in lactating dairy cows. J. Dairy Sci. 95:3781-3793.

Giordano, J. O., M. Stangaferro, R. Wijma, W. Chandler, and R. Watters. 2015. Reproductive performance of dairy cows managed with a program aimed at increasing insemination of cows in estrus based on increased physical activity and fertility of timed artificial inseminations. J. Dairy Sci. 98:2488-2501.

Giordano, J. O., M. Thomas, G. Catucuamba, M. Curler, M. Masello, M. Stangaferro, and R. Wijma. 2016. Reproductive management strategies to improve the fertility of cows with a suboptimal response to resynchronization of ovulation. J. Dairy Sci. 99:29672978

Giordano, J. O., M. Wiltbank, J. Guenther, M. Ares, G. Lopes, M. Herlihy, and P. Fricke. 2012b. Effect of presynchronization with human chorionic gonadotropin or gonadotropin-releasing hormone 7 days before resynchronization of ovulation on fertility in lactating dairy cows. J. Dairy Sci. 95:5612-5625.

Giordano, J. O., M. Wiltbank, J. Guenther, R. Pawlisch, S. Bas, A. Cunha, and P. Fricke. 2012c. Increased fertility in lactating dairy cows resynchronized with Double-Ovsynch compared with Ovsynch initiated $32 \mathrm{~d}$ after timed artificial insemination. J. Dairy Sci. 95:639-653.

Henricks, D. M., J. Long, J. Hill, and J. Dickey. 1974. The effect of prostaglandin F2 $\alpha$ during various stages of the oestrous cycle of beef heifers. J. Reprod. Fertil. 41:113-120. 
Jo, M., and J. Fortune. 2003. Changes in oxytocin receptor in bovine preovulatory follicles between the gonadotropin surge and ovulation. Mol. Cell. Endocrinol. 200:31-43.

Lima, F. S., E. Ribeiro, R. Bisinotto, L. Greco, N. Martinez, M. Amstalden, W. Thatcher, and J. Santos. 2013. Hormonal manipulations in the 5-day timed artificial insemination protocol to optimize estrous cycle synchrony and fertility in dairy heifers. J. Dairy Sci. 96:7054-7065.

Lopes, G., J. Giordano, A. Valenza, M. Herlihy, J. Guenther, M. Wiltbank, and P. Fricke. 2013. Effect of timing of initiation of resynchronization and presynchronization with gonadotropin-releasing hormone on fertility of resynchronized inseminations in lactating dairy cows. J. Dairy Sci. 96:3788-3798.

Mann, G. E. 2009. Corpus luteum size and plasma progesterone concentration in cows. Anim. Reprod. Sci. 115:296-299.

Mendonça, L. G., S. T. Dewey, G. Lopes, F. A. Rivera, F. S. Guagnini, J. P. Fetrow, T. R. Bilby, and R. C. Chebel. 2012. Effects of resynchronization strategies for lactating Holstein cows on pattern of reinsemination, fertility, and economic outcome. Theriogenology 77:1151-1158.

Moreira, F., C. Orlandi, C. Risco, R. Mattos, F. Lopes, and W. Thatcher. 2001. Effects of presynchronization and bovine somatotropin on pregnancy rates to a timed artificial insemination protocol in lactating dairy cows. J. Dairy Sci. 84:1646-1659.

Pulley, S. L., D. Keisler, and J. Stevenson. 2015. Concentrations of luteinizing hormone and ovulatory responses in dairy cows before timed artificial insemination. J. Dairy Sci. 98:6188-6201.

Pursley, J. R., M. Mee, and M. Wiltbank. 1995. Synchronization of ovulation in dairy cows using PGF $2 \alpha$ and GnRH. Theriogenology 44:915-923.

Remnant, J. G., M. Green, J. Huxley, and C. Hudson. 2015. Variation in the interservice intervals of dairy cows in the United Kingdom. J. Dairy Sci. 98:889-897.

Ribeiro, E. S., R. Bisinotto, M. Favoreto, L. Martins, R. Cerri, F. Silvestre, L. Greco, W. Thatcher, and J. Santos. 2012. Fertility in dairy cows following presynchronization and administering twice the luteolytic dose of prostaglandin F $2 \alpha$ as one or two injections in the 5-day timed artificial insemination protocol. Theriogenology 78:273-284.

Rivera, F. A., L. G. Mendonça, G. Lopes, J. E. Santos, R. V. Perez, M Amstalden, A. Correa-Calderón, and R. C. Chebel. 2011. Reduced progesterone concentration during growth of the first follicular wave affects embryo quality but has no effect on embryo survival post transfer in lactating dairy cows. Reproduction 141:333-342.

Scott, B. D. 2016. Incorporation of dairy farm survey data and epidemiological patterns for agent-based simulation modeling of dairy herd dynamics. MS Thesis. Cornell University, Ithaca, NY.
Sinedino, L. D., F. Lima, R. Bisinotto, R. Cerri, and J. Santos. 2014 Effect of early or late resynchronization based on different methods of pregnancy diagnosis on reproductive performance of dairy cows. J. Dairy Sci. 97:4932-4941.

Souza, A. H., H. Ayres, R. Ferreira, and M. Wiltbank. 2008. A new presynchronization system (Double-Ovsynch) increases fertility at first postpartum timed AI in lactating dairy cows. Theriogenology $70: 208-215$.

Souza, A. H., A. Gümen, E. Silva, A. Cunha, J. Guenther, C. Peto, D. Caraviello, and M. Wiltbank. 2007. Supplementation with estradiol-17 $\beta$ before the last gonadotropin-releasing hormone injection of the Ovsynch protocol in lactating dairy cows. J. Dairy Sci. 90:4623-4634.

Sprecher, D. J., R. Nebel, and S. Whitman. 1989. The predictive value, sensitivity and specificity of palpation per rectum and transrectal ultrasonography for the determination of bovine luteal status. Theriogenology 31:1165-1172.

Stevenson, J. S., J. Pursley, H. Garverick, P. Fricke, D. Kesler, J. Ottobre, and M. Wiltbank. 2006. Treatment of cycling and noncycling lactating dairy cows with progesterone during Ovsynch. J. Dairy Sci. 89:2567-2578.

Vasconcelos, J. L., R. Sartori, H. Oliveira, J. Guenther, and M. Wiltbank. 2001. Reduction in size of the ovulatory follicle reduces subsequent luteal size and pregnancy rate. Theriogenology 56:307-314.

Vasconcelos, J. L., R. Silcox, G. Rosa, J. Pursley, and M. Wiltbank. 1999. Synchronization rate, size of the ovulatory follicle, and pregnancy rate after synchronization of ovulation beginning on different days of the estrous cycle in lactating dairy cows. Theriogenology 52:1067-1078.

Wijma, R., M. L. Stangaferro, M. Masello, G. E. Granados, and J. O. Giordano. 2017. Resynchronization of ovulation protocols for dairy cows including or not including gonadotropin-releasing hormone to induce a new follicular wave: Effects on re-insemination pattern, ovarian responses, and pregnancy outcomes. J. Dairy Sci. 100:7613-7625.

Wiltbank, M. C., G. M. Baez, F. Cochrane, R. V. Barletta, C. R. Trayford, and R. T. Joseph. 2015. Effect of a second treatment with prostaglandin F2 $\alpha$ during the Ovsynch protocol on luteolysis and pregnancy in dairy cows. J. Dairy Sci. 98:8644-8654.

Wiltbank, M. C., and J. R. Pursley. 2014. The cow as an induced ovulator: Timed AI after synchronization of ovulation. Theriogenology $81: 170-185$. 